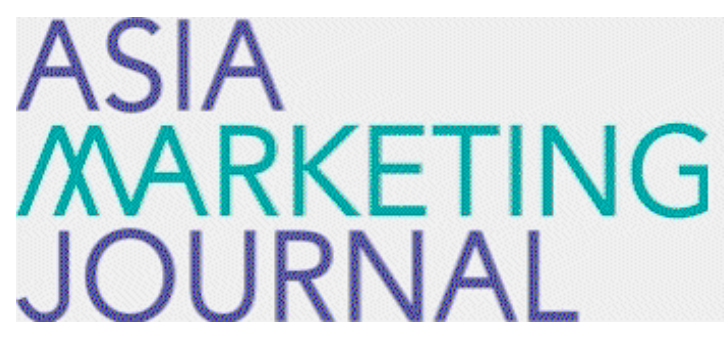

ASIA MARKETING JOURNAL

Volume 22 | Issue 3

Article 5

$10-31-2020$

\title{
How Can Customer Experience on CDJ Be Shaped?: Can Rose Be Tamed?
}

Sang mi Lee

Sang man Han

Follow this and additional works at: https://amj.kma.re.kr/journal

Part of the Marketing Commons

\section{Recommended Citation}

Lee, Sang mi and Han, Sang man (2020) "How Can Customer Experience on CDJ Be Shaped?: Can Rose Be Tamed?," Asia Marketing Journal: Vol. 22 : Iss. 3 , Article 5.

Available at: https://doi.org/10.15830/amj.2020.22.3.87

This Article is brought to you for free and open access by Asia Marketing Journal. It has been accepted for inclusion in Asia Marketing Journal by an authorized editor of Asia Marketing Journal. 


\section{How Can Customer Experience on CDJ Be Shaped?: Can Rose Be Tamed?}

Sang mi Lee*

Sang man Han**

With the development of Information Technology, customers require promptly higher quality products and services. Companies try to make newly digital marketing strategies, but there are no empirical researches on them. This article empirically presents a new perspective that companies can shape the customer decision journey ahead by coordinating customer experience. In this article, based on Elaborated Likelihood Model (ELM) theory, customer experience consists of the emotional or cognitive experience. We surveyed about 200 subjects $(N=217)$ in their 20 s and 30 s based on the International Music Industry Association's Music Listening 2019 report, then analyzed four different models (before personalization-cognitive experience, before personalization-emotional experience, after personalization- cognitive experience, after personalization-emotional experience) by JASP and R Studio. We conducted Structural Equation Model (SEM) and paired t-test. Personalization factors are about recommendation systems in Spotify. The results of survey represent that companies can shape the Customer Decision Journey (CDJ) ahead especially through enhance cognitive experience. It empirically proves Elaborated Likelihood Model (ELM). The conclusion can be drawn that 'pulling' customer experience can be a new marketing strategies in the digital era.

Keywords: Digital Marketing Strategy, Customer Decision Journey (CDJ), Personalization, Customer Experience

The fox said, "If you tame me, then we shall need each other. If, for example, you came at 4 O'clock in the afternoon, then, at 3 O'clock I shall begin to be happy."

- Antoine, 2019 -

\section{Introduction}

With the development of Information Technology(IT), digital age has arrived. The

\footnotetext{
* Mater, School of Business, SungKyunKwan University (thinkbigdata@naver.com), Corresponding Author

** Professor, School of Business, SungKyunKwan University (smhan@skku.edu)
} 
development of the IT makes companies offering promptly higher quality products and services to customers (Tanya et al., 2019). In different aspects beyond existing needs, customers require promptly higher quality products and services (Rajat et al., 2020; Tanya et al., 2019). The flow of the consumer buying decisionmaking process is away from metaphor of funnel and transforms into customer decision journey(CDJ). (David 2010; Nicolas et al., 2016). Companies should plan newly digital marketing strategy to the digital era.

For sustainably competitive companies, they need to improve value creation (Rajat et al., 2020). Till now, value creation focuses on the revenue from selling and customer satisfaction (Katherine \& Peter, 2016; Olivia et al., 2019; Rajat et al., 2020). Since the CDJ is the sum of customer experiences rather than one-time experience, a wider range of experiences are more important at the purchasing stage (David \& Dave et al., 2009; David \& Singer, 2015; Katherine \& Peter, 2016; Nicolas et al., 2016). Companies focus on the customer's role in experience in order to maximize the customer's positive experience (Katherine \& Peter, 2016). In addition, companies are shaping the consumer experience ahead by accumulating customer data to provide a more personalizing experience to customers. For example, Disney provides an experience to reduce uncertainty and frustration during the purchase stage on the pre-purchase stage to enhance their touch points (Katherine
\& Peter, 2016).

The emergence of new channels and touch points provides companies with new marketing tactics. Especially mobile is a newly important channel (Katherine \& Peter, 2016). For examples, it enables platform managers to provide tailored, time-sensitive, location-sensitive promotions in streaming service (Yakov et al., 2014) as well as personalized marketing offers. Researches on the use of mobile in the purchase funnel and CDJ have been limited and have mainly been done in practice. So empirical research on the use of the mobile channel as a touch point is required.

Streaming services that value experience rather than ownership provide experiences in real time wherever customers want (Yakov et al., 2014). However, there have been no empirical studies on how companies provide an online customer experience ahead.

We intend to show the effectiveness of a personalized mobile marketing strategy that can actively provide a positive customer experience to managers, and theoretically show new consumer behavior aspects on CDJ.

Thus, our research question is as follows.

"How can customer experience on CDJ be shaped?"

To know whether the customer experiences proactively provided by companies can influence the shaping CDJ, we provided personalized experiences during the study. In particular, 
this study focuses on streaming services that have few restrictions on providing customer experience and can be frequently exposed to customers.

We explain CDJ, customer experience, personalization, and mobile, which are the backgrounds from the previous studies, and establish hypotheses and then proceed with the research. Based on the research results, theoretical and managerial implications are discussed, and the limitations of the research and the direction for future research are presented.

\section{Research Background}

\subsection{Customer Decision Journey(CDJ)}

The existing research focuses on the customer's purchasing decision-making process taking place at one touchpoint (David \& Dave et al., 2009; David \& Singer., 2015; Katherine \& Peter, 2016: Nicolas et al., 2016). Funnel Metaphor is the concept of starting at the wide end of the funnel with many brands in the minds of consumers and narrowing them down to the last choice (David 2010). This metaphor believes that purchasing decisions are a one-off process and that companies can change consumers' behaviors and experiences from a "push" perspective (David 2010).
〈Figure 1〉 Funnel model and CDJ model of customer decision making process (David 2010)

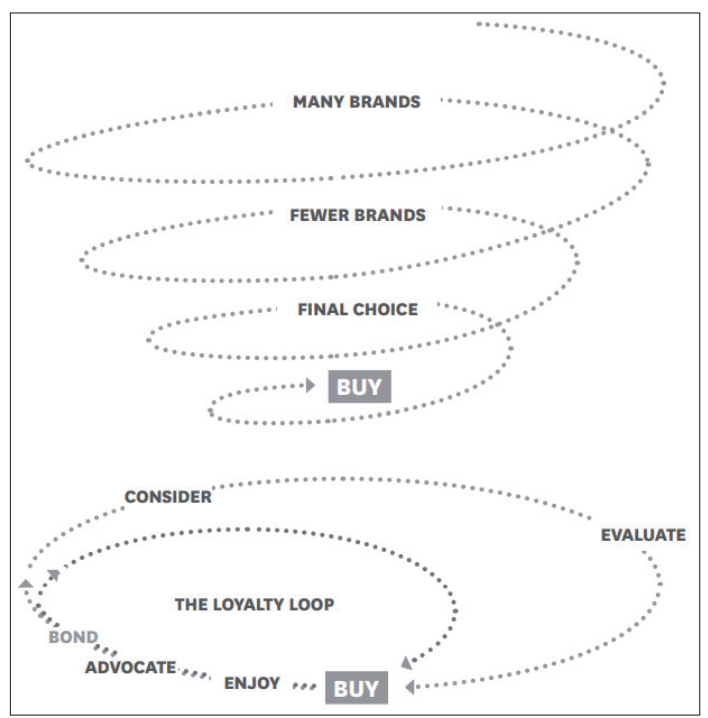

With the development of IT technology, the aspect of the customer's purchasing decision process changes. David (2010) notice that the customer's purchase decision-making process has changed into the Consumer Decision Journey $(\mathrm{CDJ})$, which is a more circular way. CDJ is a concept that narrows their choices more systematically and places importance on the role of consumers under a "pull" perspective (David 2010). Figure 1. is the picture of Funnel Metaphor and CDJ. Funnel Metaphor goes through the stages of awareness, interest, desire, and action, while CDJ goes through the stages of consider, buy, evaluate, and advocate etc (David \& Singer, 2015). In reality, the appearance of the CDJ is more complex.

CDJ is the sum of customer experiences that touch points are influenced multiple times 
without a general order (Josko et al., 2009; Shuba et al., 2010; Shuban et al., 2015). If, through experience on Touch points, consumers have a strong bond with the brand, they repurchase, except in the consider and buy stages (David \& Singer, 2015). (This is called loyalty loop) If the loyalty loop is formed in this way, the number of repurchases by which customers increase and decisions are made faster. Therefore, strategies that can bond CDJ are important to managers and marketers.

\subsection{Customer Experience as touchpoint}

On the CDJ, customers have a myriad touch points with companies in the decision-making process (Christopher \& Andre, 2007; David 2010; David \& Dave, 2009; David \& Singer, 2015; Katherine \& Peter, 2016; Nicolas et al., 2016). Therefore, the company makes it a new managerial goal to create a positive customer experience (Alex et al., 2013; Christopher \& Andre, 2007).

Customer experience is the subjective feeling of consumers on the touch point with the company (Christopher \& Andre, 2007). In Figure 2, the customer experience emerges as Philip (1967) and John Howard \& Jagdish (1969) focus on customer buying behavior process models (Katherine \& Peter, 2016). Since then, it has been contributing to customer satisfaction and loyalty, service quality, relationship marketing, customer relationship management, customer centricity and customer focus, and customer engagement (Katherine \& Peter, 2016). In particular, customer engagement focuses on the role of customers through social media (Katherine \& Peter, 2016). Recently, companies are coordinating the customer experience ahead. For example, Spotify recommends playlists to users by collecting and analyzing data of individuals with similar characteristics to previously

〈Figure 2〉 The Origins of Customer Experience in Marketing (Add to Katherine \& Peter (2016))

- Customer buying behavior process models: understanding customer experience and customer decision making as a process (1960s 1970s)

- Customer satisfaction and loyalty: assessing and evaluating customer perceptions and attitudes about an experience (1990s)

- Service quality: identifying the specific context and elements of the customer experience and mapping the customer journey (1980s)

- Relationship marketing: broadening the scope of customer responses considered in the customer experience (1990s)

- Customer relationship management (CRM): linkage models to identify how specific elements of the customer experience influence each other and business outcomes (2000s)

- Customer centricity and customer focus: focusing on the interdisciplinary and organizational challenges associated with successfully designing and managing customer experience (2000s-2010s)

- Customer engagement: recognizing the customer's role in the experience (2010s)

- Customer Decision Journey shaping: previously coordinating touchpoints for managing customer experience (This article) 
collected personal data (Daniel et al., 2018). However, existing studies do not focus on that companies can coordinate customer experience ahead. Therefore, in this study, we take the perspective of CDJ shaping, which adjusts touch points for customer experience. Richard \& John (1984) believes that consumer purchasing decisions is the perspective of funnel metaphor. Elaborated Likelihood Model(ELM) focused on two paths of persuasion, which can affect the customer experience in the customer information processing (Chih et al., 2019; Richard \& John, 1984). Two persuading paths that affect the advertisement are central route and peripheral route (Chih et al., 2019; Richard \& John, 1984). The central route through the elaborate coordination work was more affected under high involvement, and the other route through unelaborate coordination work was more affected by the lower involvement (Chih et al., 2019; Richard \& John, 1984). Thus, the elaborate coordination route, which provides high quality message, is likely to be accepted by the cognitive customers (Chih et al., 2019; Richard \& John, 1984). In contrast, the unelaborate coordination route is likely to be accepted by the emotional customers (Chih et al., 2019; Richard \& John, 1984). In this study, it is assumed that customer experience is composed of cognitive and emotional based on the ELM model.

Customer experience can be conceptualized in pre-purchase, purchase, post-purchase stages. The pre-purchase stage includes customer's interaction with the brand, category, and environment before a purchase stage (Christopher \& Andre, 2007). David (2010), David \& Marc (2015) focused on how to make 'sticky' CDJ which enables consumers to skip the initial decision-making stage then repurchase. However, Marketers often allocate more resources to "consider" and "buy" stages of the CDJ (David \& Singer, 2015). When consumer expose to an image-evoking ad, they can preplan their purchase (Katherine \& Peter, 2016). Even if the initial decision-making stage is omitted from "the loyalty loop," the initial decisionmaking stage can be an important tatics for marketers and managers. In Figure 3., the "consider" stage of the CDJ includes pre-purchase customer experience. Thus, in this article focus on the pre-purchase stage.

\subsection{Personalization}

Building on the automation capability, firms can take data from past or present interactions with customers (Alex et al., 2013; Daniel et al., 2018; Rajat et al., 2020). The firms can use it to customize customer experience (so-called Personalization) (Daniel et al., 2018; Rajat et al., 2020). Netflix and Amazon's recommendation system and algorithm are familiar examples (Daniel et al., 2018; Rajat et al., 2020). They use the customer's preference data (for example, from their rating scores, reviews, resources, or frequencies) for engaging customers or analyzing 
〈Figure 3〉 Decision making Process for Customer Journey and Experience (Katherine \& Peter (2016))

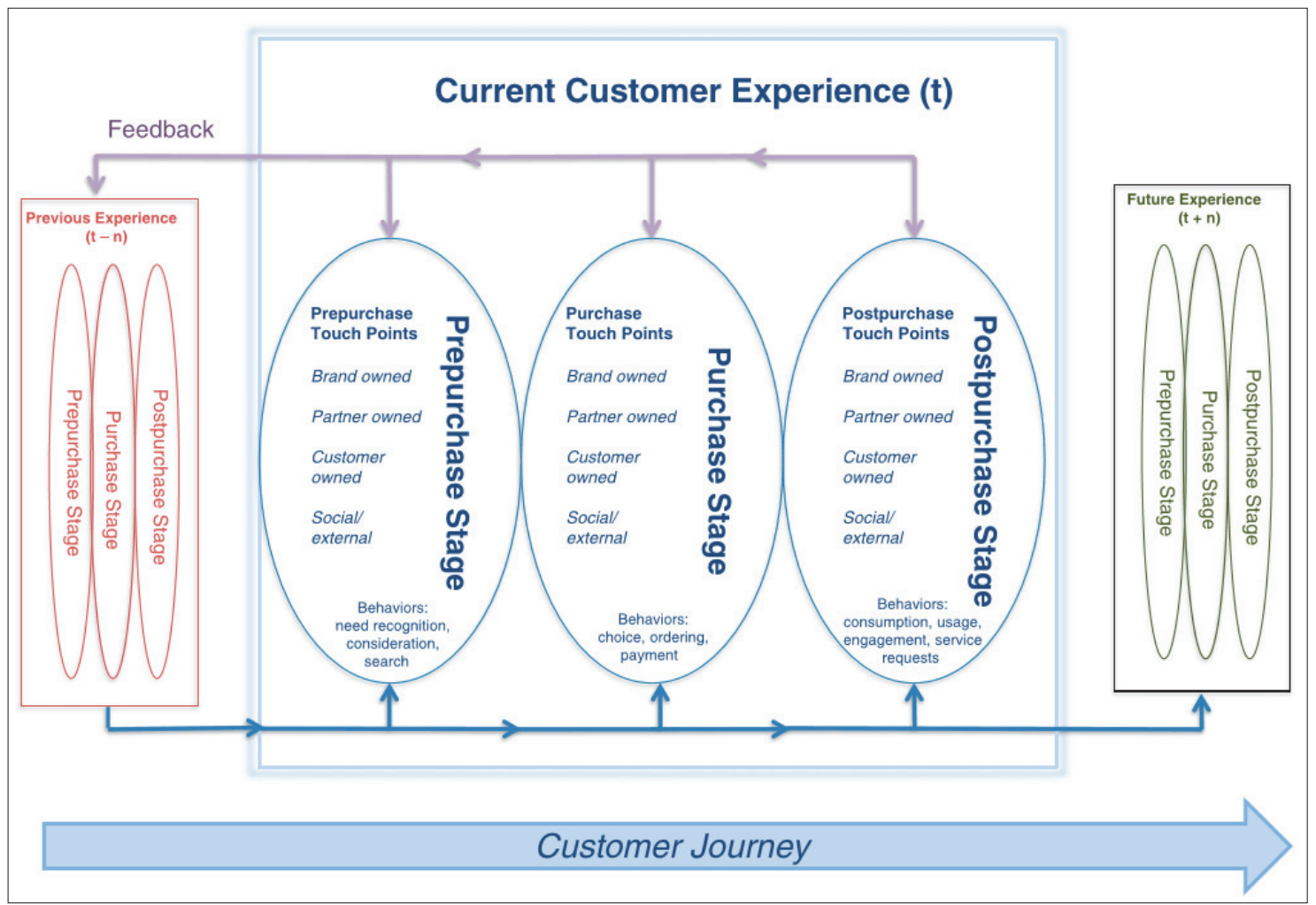

customer's behavior in real-time (Daniel et al., 2018; Rajat et al., 2020), Then the firms tailor its next interaction (Alex et al., 2013; Daniel et al., 2018; Rajat et al., 2020) on the CDJ.

Personalization may mean what changing the look of a screen, which firms can be selected by customer in real-time context (Daniel et al., 2018; Rajat et al., 2020). Thus, in the personalization perspective, the marketers and managers aim not just to improve the existing journey but to expand it (David \& Singer, 2015; Rajat et al., 2020).

The Spotify represents a successful case of personalization, and it categorizes music lists with music streaming service The streaming service can deliver a real-time, non-limited location experience to users (Daniel et al., 2018). The Spotify service offer free of charge and curate contents within Spotify apps (but, only in the shuffle mode and with the periodic advertising). Probably the free of charge give more similar experience that premium users feel to potential customer on the pre-purchase phase. When customers enter the register screen, they should choose at least five artists that they like. And they can enter the "related artists" 
screen which features grouped lists of similar style music based on tracks which users tended to listen to (Daniel et al., 2018). Additionally, the Spotify recommends the music lists on the app screen based on specific time, moods which collected by customer's tendency.

\subsection{Mobile}

Although the importance of the mobile channel is increasing, knowledge and academic research on it has been limited (Christopher \& Andre, 2007). But many firms use the mobile channel in practice (Christopher \& Andre, 2007). Thus, additional research is required about the mobile channel on the CDJ.

Mobile device channels offer new locationbased, time-sensitive features to personalizing streaming services (Yakov et al., 2014). For example, Youtube offers users time-sensitive video recommendation which can choose in new location (with no restriction). Youtube users can see video lists depends on their subscriptions lists' updates and related video that they usually watch. Mobile channel can deliver streaming experience in user's life. In music streaming service, the most of users use smart phone channel when they are listening the music (Music listening, 2019). Especially, we focus on the percentage of south Koreans that is increasing in using smart phone (Music listening, 2019). Because the famous music streaming apps of the South Korea haven't offered free full-music (They only offer part of the music), the Spotify can deliver more similar experience than other apps in South Korea which buyers can experience. Additionally, Spotify hasn't launched in South Korea yet. So we focus on the Spotify's marketing strategies on mobile.

\section{Development of hypothesis}

This section describes the foundation of this study. Variables, Hypotheses, and Model used in the study are explained below.

\subsection{Variables}

\subsubsection{Personalization}

One of the marketing strategies that customize users, considering personal characteristics and preference for improving customer experience. Especially, the Spotify's playlists recommendation system.

\subsubsection{Cognitive Experience(COG)}

An experience through central route of persuasion such as high quality messages, which can affect the cognitive customer under high involvement, based on the ELM (Chih et al., 2019, Richard \& John, 1984). 


\subsubsection{Emotional Experience(EMO)}

An experience through peripheral route of persuasion such as background models, which can affect the emotional customer under low involvement, based on the ELM (Chih et al., 2019, Richard \& John, 1984).

\subsubsection{Satisfaction(SAT)}

A customer feedback and attitude as a measurement of the customer experience.

\subsubsection{Future Experience Expectation(FUT)}

A customer experience expectation in the future, which is directly and indirectly stimulated from current experience.

\subsubsection{Purchase Intention(PUR)}

A behavioral intention that customer wants to purchase the product or service.

\subsection{Hypotheses and Model}

This article's question is "How can customer experience on CDJ be shaped?".

Personalization factors may affect customer Pre-Purchase Experience (cognitive, emotional), Satisfaction, Future Experience Expectation, and Purchase Intention on the Pre-Purchase stage of CDJ. If after personalizing figures are higher than before personalizing figures, it can empirically demonstrate the question. Thus, hypotheses are as follows.

Hypothesis 1. (H1): Before personalization, the more Pre-Purchase Experience (cognitive, emotional) firms offer, directly and indirectly the higher Future Experience Expectation customers feel on the pre-purchase stage of CDJ.

Hypothesis 2. (H2): After personalization, the more Pre-Purchase Experience (cognitive, emotional) firms offer, directly and indirectly the higher Future Experience Expectation customers feel on the pre-purchase stage of CDJ.

Hypothesis 3. (H3): Before personalization, the more Future Experience Expectation customers feel, the higher Purchase Intention customers feel on the pre-purchase stage of CDJ.

Hypothesis 4. (H4): After personalization, the more Future Experience Expectation customers feel, the higher Purchase Intention customers feel on the pre-purchase stage of CDJ.

Hypothesis 5. (H5): After personalization, Satisfaction, Future Experience Expectation, Purchase Intention is more stimulated than before personalization.

Before or After applying personalization factors on the CDJ, we compared the degree of answers. The Figure 4 is models of study. Start with applying personalization factors or not, we assumed that subjects rated the Pre-Purchase Experience (Cognitive, Emotional), Satisfaction, 
〈Figure 4〉 Model: Before Personalization/After Personalization

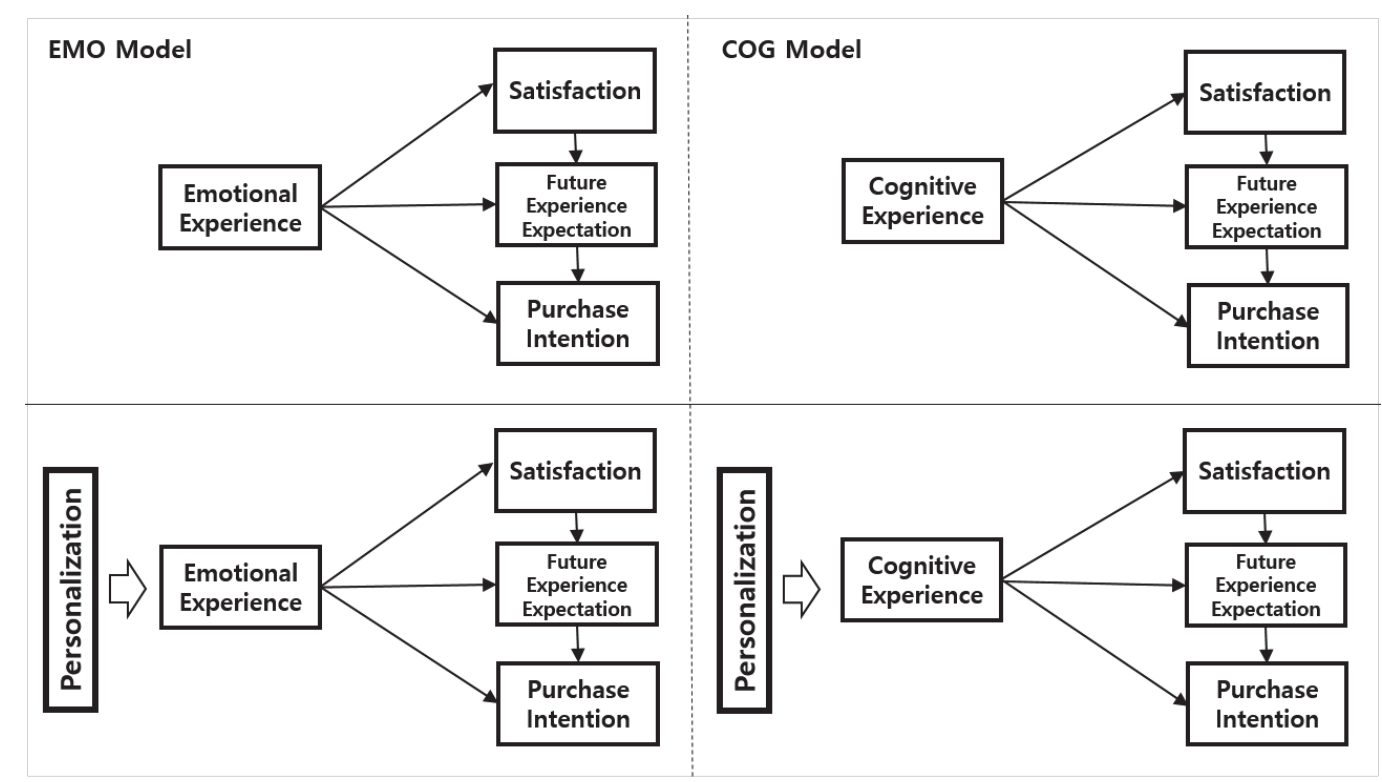

Future Experience Expectation, Purchase Intention progressively on the pre-purchase phase of CDJ. In order to meet the customer changing needs, managers and marketers should be developed and found marketing strategies. But, recently existing studies have primarily paid attention to customer engagement (Christopher \& Andre, 2007). This articles are helpful for managers and marketers in that no previous research has paid attention to the perspective of empirically shaping the proactive customer experience.

\section{Overview of study}

The study was conducted on 217 Koreans in their 20s and 30s (male: 97, female: 120) from December 14 to 18, 2019. We limited the samples of customers in their 20s and 30s based on the International Music Industry Association's Music Listening 2019 report. They were encouraged to respond to the online questionnaire form (7 point Likert scale) over the mobile, and each respondent was given a small gift certificate. For the questionnaire of this study, the theoretical contents and questionnaire sentence presented in the prior research papers were referred to. With the exception of 18 data loss, 199 subjects were respectively assigned to a 2 (personalization: yes or no) X 1 factorial design. The research context is when subjects need to choose a music streaming mobile app that provides music streaming service. 


\subsection{Methodology and Model}

\section{Participants were placed in a virtual situation} where they downloaded music streaming service apps and used them before making a purchase choice. This study conducted by scenario based survey to see the consumer's reaction according to whether the personalization factor was applied. In the Figure 5, participants were required to imagine using the basic service provided by the music streaming service apps. Then they moved to the Figure 6, second scenario. They use the music streaming services app which applied personalization factors. Differentiations of two scenarios are personalization factors. In the scenario 2, there are Spotify's personalizing marketing tactics. The bold sentences are personalizing factors in Figure 6. The users were recommended the playlists based on their and similar user's preference or tendency.

\title{
〈Figure 5〉 Scenario 1: Before Personalization
}

\begin{abstract}
$<$ Scenario 1>
Imagine the time to choose an app that provides music streaming services. You started looking for a music streaming service and after a bit of surfing the web, you downloaded a few music streaming service apps. As an alternative, all the music streaming service apps you find can listen to the entire music for free and compose a list of music you want to listen to, but they are only provided in 'Shuffle Mode' and show ads every 5 to 10 seconds every 30 minutes. When you purchase the premium service of music streaming, the advertisement disappears, you can listen to the music in the order you want, the quality of the sound source increases, and you can download the sound file infinitely and listen offline. We assume that all prices are within a reasonable budget range for you to think of, and that the terms of the contract are all paid monthly, and there is no difference between providers. You want to use the following apps that offer free music streaming services. This music streaming app provides the latest domestic/overseas music and Top 100 charts on the Home screen, and you can find the songs and artists you want through the search function. For a clearer understanding, please refer to the figures that embody the following screen.
\end{abstract}

\section{〈Figure 6〉 Scenario 2: After Personalization}


Figure 7 is the pictures which are embodied for helping intuitive understanding about scenarios. In this scenario, a specific brand name was not presented, in order to avoid bias that may occur due to the brand recognition of the participants (Umut et al., 2008). In addition, we have unified the contracts and terms of the participants because the contracts, terms and price range are complex and varied by music streaming service providers. Price-conscious customers recognize the real benefits of searching multiple channels that can benefit from the moment of purchase (Umut et al., 2008). On the other hand, customers who perceive the scarcity of a product or service perceive little of the benefits of a search (Umut et al., 2008). Therefore, additional explanations, which each alternative is included in their budget to avoid price bias when the customer's characteristics are price-conscious, have been added (Umut et al., 2008).

This study conducted a survey using an online questionnaire form to test the hypothesis, and analyzed the data obtained through the survey using R studio \& JASP 0.14.0.0. Because this study is one-group pretest-posttest design, for valid survey results, this study conducted structural equation model (SEM) test as well as paired t-test. Since this study consisted of scenarios of personalization, analysis was conducted

〈Figure 7〉 Embodied app screen images (Scenario1, Scenario2)

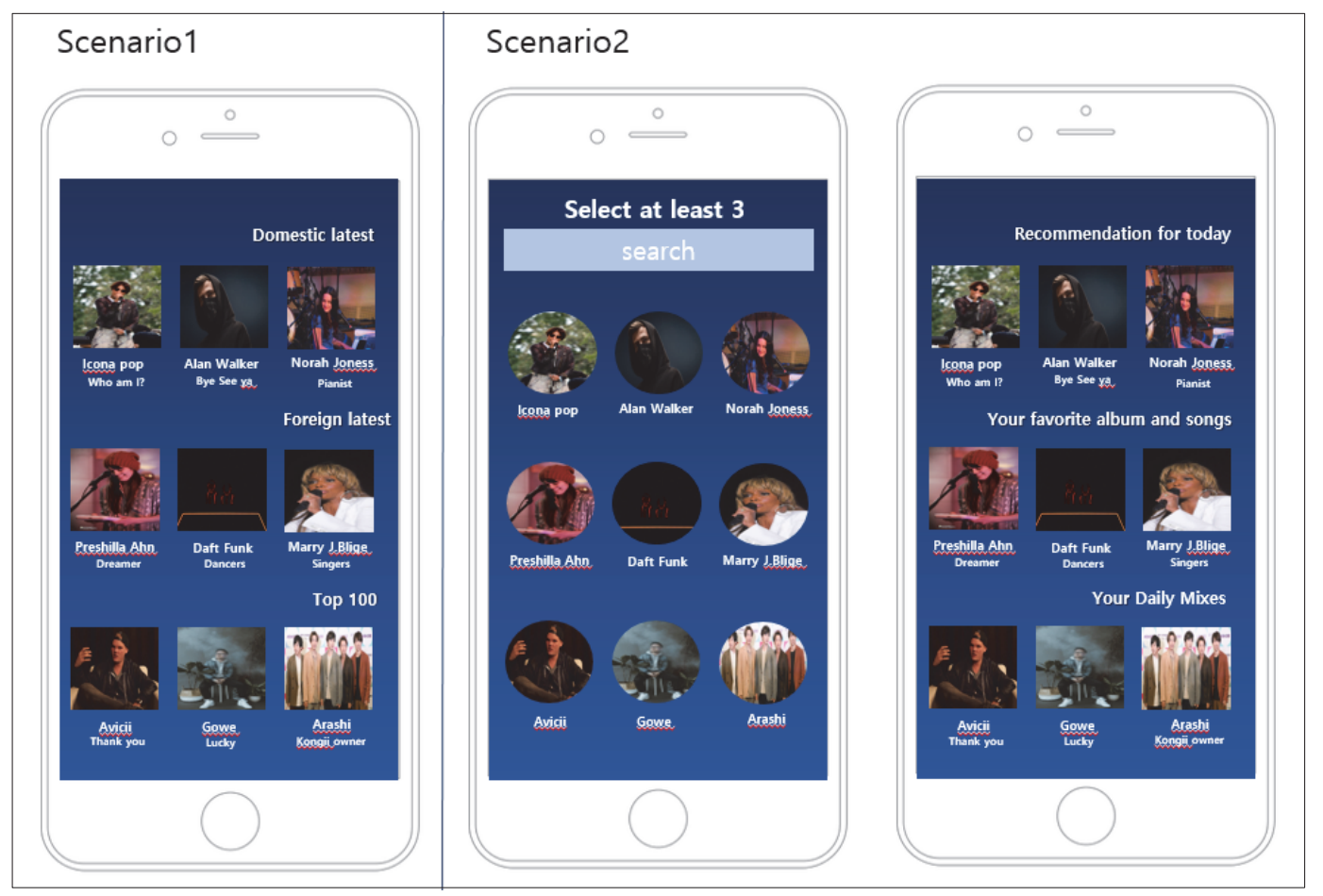


separately before and after personalization.

\subsection{Analysis and Results}

Table 2 presents description, factor analysis results (mean, standard deviation), P-value of each factor, and R-square in SEM. In factor analysis, we remove some factors (EMO4, FUT5) in case of factors lack consistency. Factor Loadings are all over 0.5, and almost over 0.7, so its validity is proved. In table 2, P-value means the latent variable's significance. All $\mathrm{P}$-value are under 0.05 , and almost under 0.01 .

Table 1 describes fit of the model. All RMSEA are under 0.01 , and all CFI, TLI are under 0.09. So, this model is fit. The Cronbach's alpha value for the whole is 0.9717 , and its figure is 0.96 or higher than it when we remove each element.

Figure 8. and Table 3. depict results of the path model. In Figure 8., upper models are before personalization models and lower models are after personalization models.

Before personalization in COG Model, except COG $\rightarrow$ FUT path, all paths are significant.
But after personalization, FUT also doesn't significantly affect PUR. Before personalization, COG is directly affect SAT and PUR, indirectly affect FUT and PUR. After personalization, COG doesn't indirectly affect FUT. Before personalization in EMO Model, only EMO $\rightarrow$ SAT, EMO $\rightarrow$ PUR path are significantly affect. But after personalization, EMO $\rightarrow$ PUR doesn't significantly affect and FUT $\rightarrow$ PUR path is significant. Before personalization, EMO directly affect SAT and PUR, FUT directly affect PUR. So COG Model proves all Hypothesis. But EMO Model proves only Hypothesis 2, 4.

Table 4. depicts paired t-test results. All results are significant. So all factors are affected by personalization and it proves Hypothesis 5 .

Synthesis of all results represents (1) cognitive experience affect future experience expectation and purchase intention, (2) emotional experience doesn't affect future experience expectation, but does purchase intention, (3) after personalization in EMO Model, future experience expectation affects purchase intention, (4) All variables are affected by personalization. Thus, this study can shape the CDJ by pre-purchase experience.

〈Table 1〉 Evaluating Model Fit

\begin{tabular}{ccccccccccc}
\hline \multirow{2}{*}{ Factor } & \multicolumn{2}{c}{$\mathrm{X}^{2}$} & \multicolumn{2}{c}{$\mathrm{P}$} & \multicolumn{2}{c}{ RMSEA } & \multicolumn{2}{c}{ CFI } & \multicolumn{2}{c}{ TLI } \\
& Before & After & Before & After & Before & After & Before & After & Before & After \\
\hline EMO & 129.361 & 117.686 & $* * *$ & $* * *$ & 0.063 & 0.056 & 0.979 & 0.985 & 0.973 & 0.981 \\
COG & 158.190 & 158.190 & $* * *$ & $* * *$ & 0.066 & 0.066 & 0.979 & 0.979 & 0.974 & 0.974 \\
\hline Criteria & & & & & $\langle 0.1$ & $\langle 0.1$ & $\langle 0.9$ & $<0.9$ & $<0.9$ & $<0.9$ \\
\hline
\end{tabular}

${ }^{* * *}=\mathrm{P}<0.01,{ }^{* *}=\mathrm{P}<0.1$ 


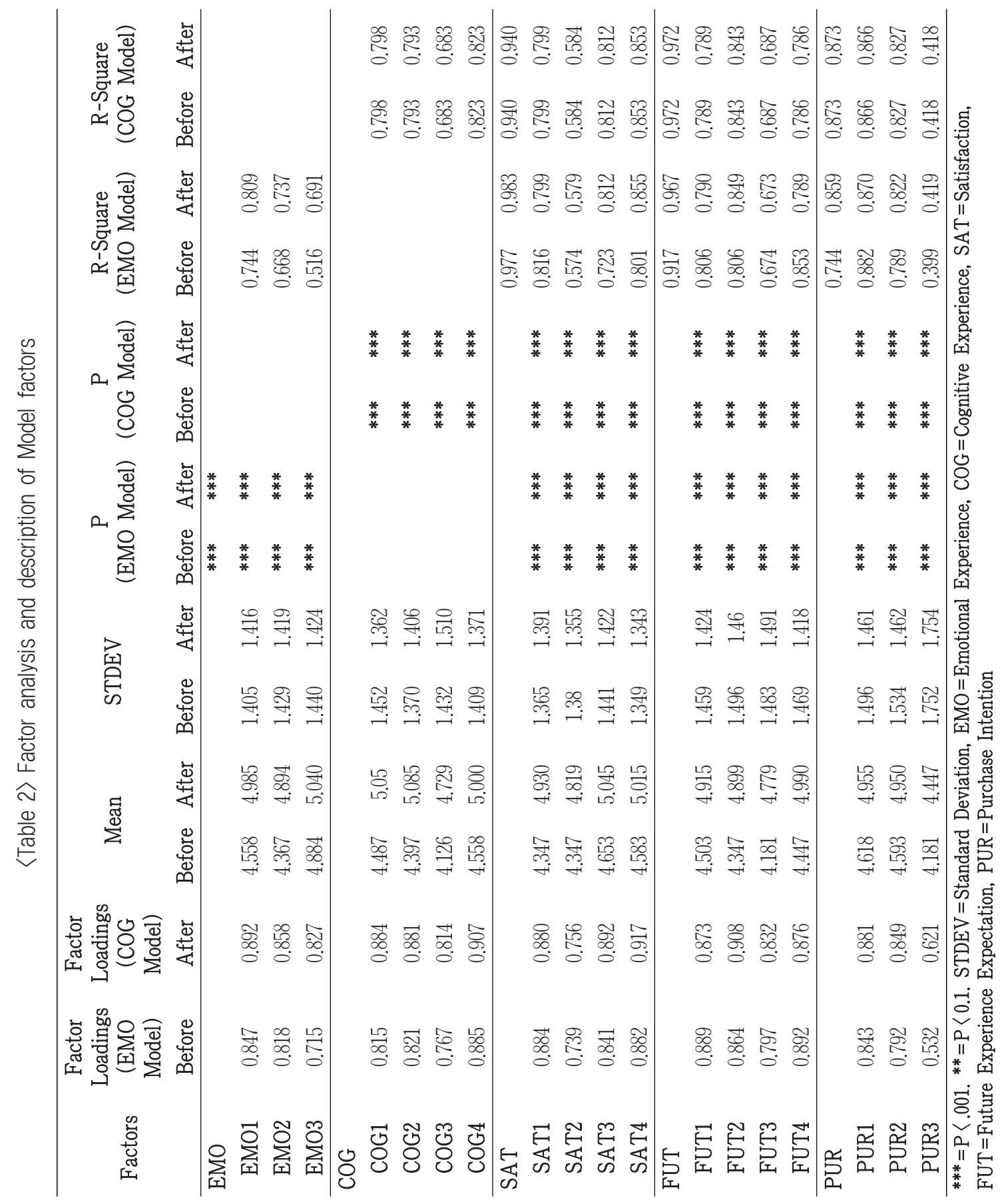


〈Figure 8〉 Path models of the before personalization/after personalization.

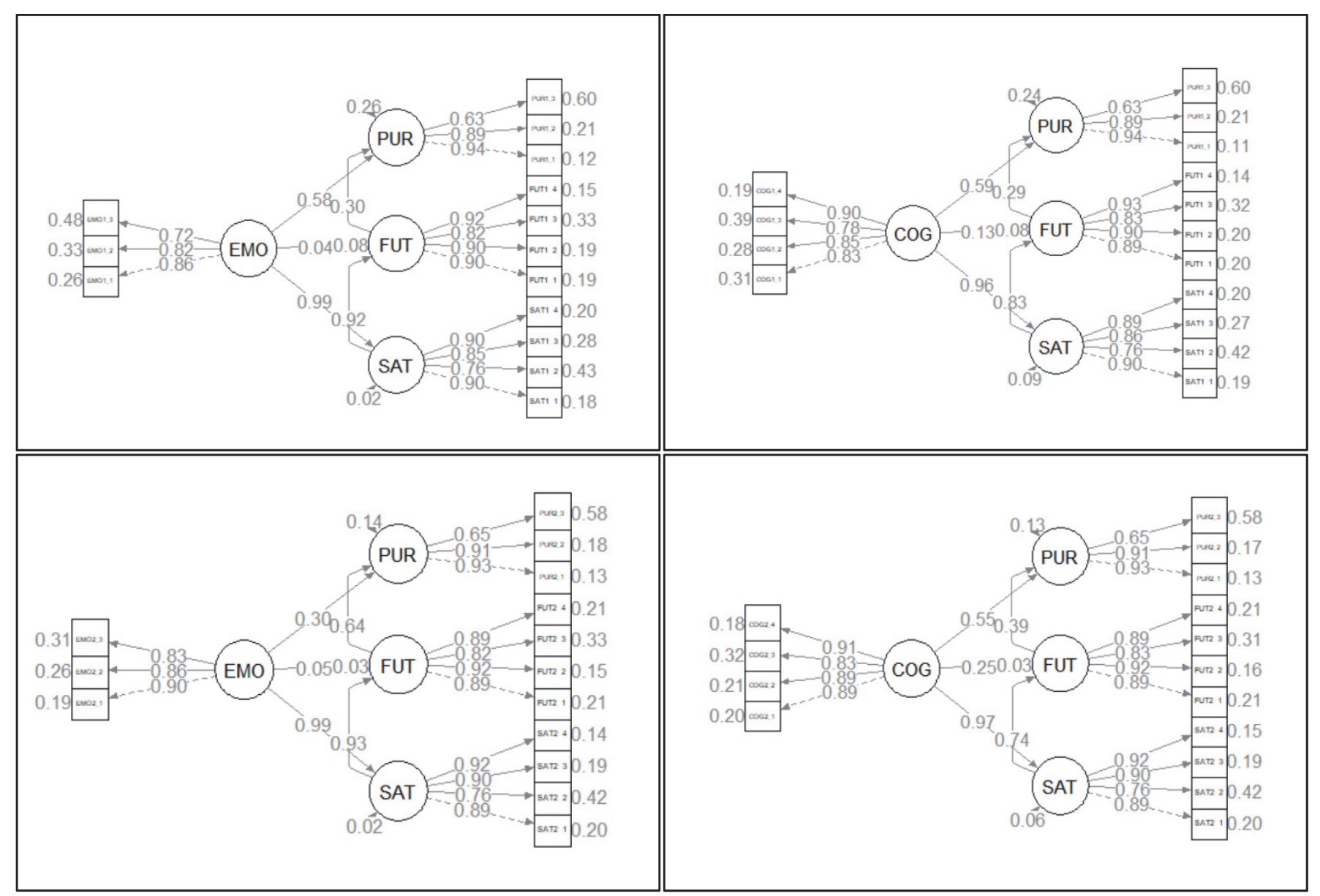


〈Table 3〉 Paths coefficient and significance of the Models

\begin{tabular}{|c|c|c|c|c|c|c|c|c|c|}
\hline \multirow{2}{*}{ Path } & \multicolumn{2}{|c|}{ B } & \multicolumn{2}{|c|}{$\mathrm{P}$} & \multirow{2}{*}{ Path } & \multicolumn{2}{|c|}{ B } & \multicolumn{2}{|c|}{$\mathrm{P}$} \\
\hline & Before & After & Before & After & & Before & After & Before & After \\
\hline $\mathrm{SAT} \sim$ & & & & & $\mathrm{SAT} \sim$ & & & & \\
\hline COG & 0.976 & 0.991 & $* * *$ & $* * *$ & EMO & 1.005 & 0.968 & $* * *$ & $* * *$ \\
\hline FUT & & & & & FUT & & & & \\
\hline COG & 0.146 & 0.257 & 0.487 & 0.208 & EMO & 0.038 & 0.053 & 0.963 & 0.945 \\
\hline SAT & 0.879 & 0.757 & $* * *$ & $* * *$ & SAT & 0.98 & 0.948 & 0.231 & 0.229 \\
\hline PUR & & & & & PUR & & & & \\
\hline $\mathrm{COG}$ & 0.693 & 0.611 & $* * *$ & $* *$ & EMO & 0.669 & 0.317 & $* *$ & 0.392 \\
\hline FUT & 0.317 & 0.424 & $* *$ & 0.114 & FUT & 0.316 & 0.684 & 0.187 & $* *$ \\
\hline
\end{tabular}

〈Table 4〉 Results of the paired t-test

\begin{tabular}{|c|c|c|c|c|c|c|c|c|c|c|c|c|c|c|c|c|c|c|}
\hline Before & COGI_1 & COG1_2 & COGI_3 & COGI_4 & EMO1_ & EMO1_2 & EMO1 & SATI_1 & SAT1 & SAT1_3 & SATI_A & FUT1_1 & FUT1_2 & FUT1_3 & FUT1_\& & PUR1_1 & PURI & PUR1_3 \\
\hline After & COG2_1 & COGZ_2 & COGZ_ 3 & COG2_ 4 & EMO2_1 & EMO2_2 & EMO2_3 & SAT2_1 & SATZ_2 & SAT2_3 & SATZ_A & FUT2_1 & FUT2_2 & FUT2_3 & FUT2_4 & PUR2_1 & PUR2_2 & PUR2_3 \\
\hline$t$ & -6.812 & -7.778 & $-6,365$ & -5.199 & -4.779 & -6.264 & -1.888 & -7.226 & -5.346 & $-4,887$ & $-5,721$ & $-4,721$ & -5.993 & -5.997 & -6.105 & $-4,049$ & $-3,986$ & -2.76 \\
\hline p & $* * *$ & $* * *$ & $* * *$ & $* * *$ & $* * *$ & $* * *$ & ** & $* * *$ & $* * *$ & $* * *$ & $* * *$ & $* * *$ & $* * *$ & $* * *$ & $* * *$ & $* * *$ & $* * *$ & ** \\
\hline
\end{tabular}
${ }^{* * *}=\mathrm{P}<.001 .{ }^{* *}=\mathrm{P}<0.1$.

Especially, study empirically prove existing theory, ELM. We find cognitive experience, which affected by the elaborate coordination route, goes through all paths in Model. It may mean consumers who are affected by cognitive experience has high involvement. In contrast, the emotional experience, which affected by the unelaborate coordination route, goes through partial paths in Model. It may mean consumers who are affected by emotional experience has low involvement.

Thus, synthesis the results of this survey represent that companies can shape the consumer decision journey ahead especially through enhance cognitive experience.

\section{Implication and Conclusion}

\subsection{Implication}

Numerous researches have explored CDJ extensively. Researches consistently suggest that ICT abilities can help to create improving competitive capability and contribute to enhancing positive customer experience. Till now, even though CDJ theory is advocated, researches has explored decision making process of funnel metaphor. And researches which focused on customer experience haven't focused on shaping CDJ. However, studying and closely examining 
the effect of CDJ and experience is required. Companies try to shape CDJ by previously coordinating customer experience. This study offers insights for managers or marketers who are interested in it can be empirically proved and will influence their companies.

While previous studies focus only on the purchase intention and loyalty of customer experience (Christopher \& Andre, 2007). this study focuses on the level of future experience.

The results indicate that customer's experience influences future experience expectation and how to lead higher mobile marketing effect on the CDJ over the satisfaction and one purchase decision process by using personalization factors. Thus, this study can give an incentive for companies to change the way they manage their touch points in the customer decisionmaking journey. (Push perspective $\rightarrow$ Pull perspective)

\subsection{Conclusion}

This paper empirically presents a new perspective that companies can shape the customer decision journey ahead by coordinating consumer experience. We surveyed about 200 subjects $(N=217)$ in their 20 s and 30 s, then analyzed four different models (before personalization-cognitive experience, before personalization-emotional experience, after personalization-cognitive experience, after personalization-emotional experience) by JASP and R Studio. We conducted structural equation model (SEM) and paired t-test. Personalization factors are about recommendation systems in Spotify. The results of survey represent that companies can shape the consumer decision journey ahead especially through enhance cognitive experience.

The conclusion can be drawn that 'pulling' customer experience can be a new marketing strategies in the digital era.

\subsection{Limitations}

First, this study don't analyze the entire customer's decision-making journey simultaneously, but focuses on one touch point and the situation of the customer experience on the pre-purchase stage. It has been shown that the previous experience can affect the future experience, but the customer experience can lead to not only the pre-purchase stage, but also the purchase and post-purchase stages, and can affect the entire customer decision-making journey.

Second, there are limitations in selecting samples. The samples were selected based on the Music Listening 2019 report of the International Music Industry Association, but the future researches can study on a wider variety of sample groups.

Third, there are limitation on the channels. Although we focus on mobile apps that provide music streaming services, the channels 
that actually influence the CDJ range from online or offline to omni-channels.

These three limitations are worth addressing in the future studies.

$\langle$ Received September 21. 2020〉

〈Accepted October 31. 2020〉

\section{References}

Behera, R. K., Gunasekaran, A., Gupta, S., Kamboj, S., \& Bala, P. K. (2020). Personalized digital marketing recommender engine. Journal of Retailing and Consumer Services, 53, 101799. https://doi.org/10.1016/j.jretconser. 2019.03.026. (http://www.sciencedirect.com /science/article/pii/S0969698918307987)

Bart, Y., Stephen, A. T., \& Sarvary, M. (2014). Which products are best suited to mobile advertising? A field study of mobile display advertising effects on consumer attitudes and intentions. Journal of Marketing Research, 51(3), 270-285. https://doi.org/10.1509/jmr. 13.0503

Brakus, J. J., Schmitt, B. H., \& Zarantonello, L. (2009). What is it? how is it measured? does it affect loyalty. Journal of Marketing, 73(3), 52-68. https://www.jstor.org/stable/ 20619022

Court, D., Elzinga, D., Mulder, S., \& Vetvik, O. J. (2009). The consumer decision journey. Mckinsey Quarterly, June 1, 2009. https:// www.mckinsey.com/business-functions/ marketing-and-sales/our-insights/theconsumer-decision-journey

Edelman, D. C. (2010). Branding in the digital age: You're spending your money in all the wrong places. Harvard Business Review, December 2010. https://hbr.org/2010/12/ branding-in-the-digital-age-youre-spending -your-money-in-all-the-wrong-places

Edelman, D. C., \& Singer, M. (2015). Competing on customer journeys. Harvard Business Review, November 2015, 88-100. https:// hbr.org/2015/11/competing-on-customerjourneys

Exupery, A. D. S. (2019). The little prince. Gigova, T., Valeva, K., \& Alexieva, V. N. (2019). Digital transformation-Opportunity for industrial growth. 2019 International Conference on Creative Business for Smart and Sustainable Growth(CREBUS), IEEE. https://doi.org/10.1109/CREBUS.2019. 8840065

Howard, J. A., \& Sheth, J. N. (2001). A Theory of Buyer Behavior. Marketing: Critical Perspectives on Business and Management, 3, 81. https://books.google.co.kr/books?hl $=\mathrm{ko} \& \mathrm{lr}=\& \mathrm{id}=$ HLuolsawoA YC\&oi $=$ fnd $\& p g=$ PA81\&dq $=\mathrm{a}+$ theory + of + buyer + behavior \&ots = IfiB9-1AXy \&sig = I5RJ 9vkREh6Ze8Kdf9mQd5ERFlg\&redir_esc $=\mathrm{y} \# \mathrm{v}=$ onepage \&q=a\%20theory \%20of $\% 20$ buyer\%20behavior \&f $=$ false

Konus, U., Verhoef, P. C., \& Neslin, S. A. 
(2008). Multichannel Shopper Segments and Their Covariates. Journal of Retailing, 84, 398-413. https://doi.org/10.1016/j.jretai. 2008.09.002

Kotler, P. (1997). Marketing management: Analysis, planning, implementation and control. http://live2.cyclingnews.com/trxfzlw /20-lukas-little/marketing-managementanalysis-planning-implement-0132435101.pdf

Lemon, K. N., \& Verhoef, P. C. (2016). Understanding customer experience through the customer journey. Journal of Marketing: AMA/MSI Special Issue, 80, 69-96. https:// doi.org/10.1509/jm.15.0420

Lu, C. C., Wu, I. L., \& Hsiao, W. H. (2019). Developing customer product loyalty through mobile advertising: Affective and cognitive perspectives. International Journal of Information Management, 47, 101-111. https://doi.org/10.1016/j.ijinfomgt.2018. 12.020

Maechler, N., Neher, K., \& Park, R. (2016). From touchpoint to journeys: Seeing the world as customers do. Mckinsey Quarterly, March 2016, 1-10. https://www.mckinsey. com/business-functions/marketing-andsales/our-insights/from-touchpoints-tojourneys-seeing-the-world-as-customers-do

Meyer, C., \& Schwager, A. (2007). Understanding customer experience. Harvard Business Review, article. https://d1wqtxts1xzle7. cloudfront.net/35132402/FINAL_HBR_ Understanding_Customer_Experience.pdf?
$1413332186=$ \& response - content - disposition = inline $\% 3 \mathrm{~B}+$ filename\%3DUnderstanding _Customer_Experience.pdf\&Expires $=$ $1604079240 \&$ Signature $=$ Qw - KvsBChh AhjUWF39IiZVeTCt4tkRDXoSMp7FHAM rpFyXdHSgEoWAsIHf52KSpdHXU80yf 64oodVRKNGfLegkYbrA16YfaPuapTa1KSuIWYZlm4euQfAf9 ycPshvriBboX 7oSW4rFfTfKxcG-zZkgmsaza2EpzdKK yzAJ3nhjDTFucW 0EiMnjCbNGUIvpI glzP5A uprVh2L4hwWbEgD2Jm5AvaK uYJIyM5eotH113oYcRwGYcar TdK2T m9euuK1TitCbcqlR7OXFY8J-gpg6X0ROV 8sM-M3Hb5j58vwOOCvOADmY665O3 NRmiQZZzL5LetY8p5wujsngCpA $\&$ Key-Pair-Id = APKAJLOHF5GGSLRBV4ZA Music listening 2019. IFPI, https://www.ifpi. org/wp-content/uploads/2020/07/MusicListening-2019-1.pdf

Petit, O., Velasco, C., \& Spence, C. (2019). Digital sensory marketing: Integrating new technologies into multisensory online experience. Journal of Integrative Marketing, 45, 42-61. https://doi.org/10.1016/j.intmar. 2018.07.004

Petty, R. E. \& Cacioppo, J. T. (1984). The elaboration likelihood model of persuasion. Advances in Consumer Research, 11, 673675. https://www.acrwebsite.org/volumes /6329/volumes/v11/NA\%20-\%2011

Rawson A., Duncan E., \& Jones C. (2013). The truth about customer experience. Harvard Business Review, September 2013, 1-11. 
https://hbr.org/2013/09/the-truth-aboutcustomer-experience

Skog, D. A., Wimelius, H., \& Sandberg, J. (2018). Digital service platform evolution: How spotify leveraged boundary resources to become a global leader in music streaming. Hawaii International Conference on System Sciences, 51, 4564-4573. http:// dl.handle.net/10125/50465

Srinvasan, S., Rutz, O. J., \& Pauwels, K. (2015). Paths to and off purchase: Quantifying the impact of traditional marketing and online consumer activity. American Marketing Association, 44, 440-453. http://doi.org/ 10.1007/s11747-015-0431-z

Srinvasan, S., Vanhuele, M., \& Pauwels, K. (2010). Mind-set metrics in market response models: An integrative approach. Academy of Marketing Science, 47(4), 672-684. http://www.jstor.org/stable/20751532

https://pixabay.com/ko/vectors/\%EC\%95\% 84\%EC\%9D\%B4\%ED\%8F\%B0-\%EC\% 95\%88-\%ЕB\%93\%9C-\%ЕB\%A1\%9C\% ЕC\%9D\%B4\%ЕB\%93\%9C-\%ЕC\%8A\% $\mathrm{A} 4 \% \mathrm{ED} \% 85 \% 90 \% \mathrm{EC} \% 8 \mathrm{~B} \% \mathrm{~A} 4-1459087 /$

https://upload.wikimedia.org/wikipedia/ commons/thumb/4/4e/Icona_Pop_003 - -DC_Capital_Pride_street_festival -_2013-06-09_\%289013107236\%29. jpg/1024px-Icona_Pop_003___DC_ Capital_Pride_street_festival___2013 -06-09_\% 289013107236\%29.jpg https://upload.wikimedia.org/wikipedia/ commons/thumb/b/bc/Alan_Walker_ press_shot.jpg/1024px-Alan_Walker_ press_shot.jpg

https://upload.wikimedia.org/wikipedia/ commons/thumb/5/5d/Norah_Jones_at _Bright_Eyes_2007.jpg/1024px-Norah _Jones_at_Bright_Eyes_2007.jpg

https://upload.wikimedia.org/wikipedia/ commons/d/d9/Michael_Jackson_1984 _\%28cropped\%29.jpg

https://upload.wikimedia.org/wikipedia/ commons/thumb/9/90/ARASHI_ mengguncang_Jakarta\%21_1m_5s.jpg/ 1024px-ARASHI_mengguncang_Jakarta $\% 21 \_1 \mathrm{~m} \_5 s . j p g$

https://upload.wikimedia.org/wikipedia/ commons/thumb/d/d7/DaftPunk_Never EverLand_Sydney_2007.JPG/1024pxDaftPunk_NeverEverLand_Sydney_ 2007.JPG

https://upload.wikimedia.org/wikipedia/ commons/thumb/9/9f/Mary_____Blige_ ju12007.jpg/512px-Mary_J._Blige_ jul2007.jpg

https://upload.wikimedia.org/wikipedia/ commons/thumb/7/79/Avicii_interview _for_GlobalGrindTV.jpg/1024px-Avicii _interview_for_GlobalGrindTV.jpg

https://upload.wikimedia.org/wikipedia/ commons/thumb/1/10/Gowe_2019.jpg/ 1024px-Gowe_2019.jpg 